\title{
CARCINOMA EPIDERMÓIDE DE PALATO MOLE E REBORDO ALVEOLAR INFERIOR - RELATO DE CASO COM EXPRESSIVO ATRASO DE DIAGNÓSTICO
}

Danielle DEL SANTO, Cassius Carvalho TORRES-PEREIRA, José Miguel AMENABAR, Cleto Mariosvaldo PIAZZETTA

O presente trabalho descreve o caso de um paciente do sexo masculino, 53 anos de idade, leucoderma, que foi encaminhado por uma unidade básica de saúde para a clínica de Estomatologia da UFPR com queixa de dor na orofaringe e dificuldades na deglutição. Durante a anamnese o paciente afirmou ser tabagista há 35 anos, sendo a freqüência do hábito de aproximadamente dois maços de cigarros por dia. Ao exame clinico extrabucal não apresentava linfonodos palpáveis e não foram detectadas outras anormalidades. Ao exame clínico intrabucal, apresentava extensa massa nodular com ulceração central, medindo aproximadamente $8 \mathrm{~cm}$ no maior diâmetro e que acometia o palato mole, rebordo alveolar inferior e região sublingual posteriores do lado esquerdo. Relatava evolução de aproximadamente 4 meses. Foram coletados dois fragmentos de tecido através de biópsia incisional. Dadas as condições de intenso acúmulo de biofilme e presença de restos radiculares, optou-se também por adequação imediata do meio bucal, sendo ainda medicado com paracetamol 750mg e colutório de clorexidina. O exame anatomopatológico confirmou a hipótese de diagnóstico de carcinoma epidermóide. Serão discutidas as manifestações clássicas do câncer de boca neste paciente, bem como os fatores que caracterizaram o intenso atraso do diagnóstico.

Palavras-chave: carcinoma de células escamosas, carcinoma espinocelular, carcinoma de células planas. 